\title{
Phase angle and Mediterranean diet in patients with acne: Two easy tools for assessing the clinical severity of disease
}

Luigi Barrea ${ }^{1,2^{*}+}$ (D), Marianna Donnarumma ${ }^{3 \dagger}$, Sara Cacciapuoti ${ }^{3}$, Giovanna Muscogiuri2 ${ }^{2,4}$, Ludovica De Gregorio ${ }^{3}$, Chiara Blasio ${ }^{3}$, Silvia Savastano ${ }^{2,4}$, Annamaria Colao ${ }^{2,4,5}$ and Gabriella Fabbrocini ${ }^{3}$

\begin{abstract}
Background: Acne is a chronic, inflammatory and debilitating skin disorder. Dietary factors and nutritional status are among the exacerbating factors of acne. Phase angle (PhA), a direct measure of Bioelectrical Impedance Analysis (BIA), represents an indicator of the chronic inflammatory state. The Mediterranean diet (MD) is a healthy dietary pattern that can exert anti-inflammatory effects in several inflammatory diseases. We aimed to investigate the difference in $\mathrm{PhA}$ and adherence to the MD and their associations with the severity of acne in a sample of naive treatment patients with acne compared to control group.
\end{abstract}

Materials: In this cross-sectional, case-control, observational study, we enrolled 51 patients with acne and 51 control individuals. Body composition was evaluated by a BIA phase-sensitive system (50 kHz BIA 101 RJL, Akern Bioresearch, Florence, Italy, Akern). For adherence to the MD, we have used the PREvención con Dleta MEDiterránea (PREDIMED) questionnaire. The clinical severity of acne was assessed by using the global acne grading system (GAGS), a quantitative scoring system to assess acne severity.

Results: Patients with acne had a worse body composition, in particular smaller PhA ( $p=0.003)$, and a lower adherence to the MD $(p<0.001)$ than the control group, in spite of no differences in gender, age and BMl between the two groups. Stratifying patients with acne according to GAGS categories, both PhA ( $p=0.006)$ and PREDIMED score $(p=0.007)$ decreased significantly in severe acne than mild/moderate acne. The GAGS score was negative correlations with PhA $(r=-0.478, p<0.001)$ and PREDIMED score $(r=-0.504, p<0.001)$. The results of the multivariate analysis showed PhA and PREDIMED score were the major determinants of GAGS score $(p<0.001)$. The receiver operator characteristic (ROC) analysis reporting a value of $\mathrm{PhA}$ of $\leq 6.1^{\circ}$ and a PREDIMED score of $\leq 9$ identified patients with acne with the highest clinical severity of the disease.

Conclusions: Novel correlations were reported between PhA and the degree of adherence to the MD with acne severity. Of interest, PhA and PREDIMED scores might represent possible markers of the severity of acne in a clinical setting. This study highlights how a cooperation between dermatologist and nutritionists might provide a combination key in the complex management of acne patients.

\footnotetext{
*Correspondence: luigi.barrea@unina.it

†Luigi Barrea, Marianna Donnarumma and Sara Cacciapuoti contributed equally to this work

${ }^{1}$ Dipartimento di Scienze Umanistiche, Centro Direzionale, Università

Telematica Pegaso, Via Porzio, isola F2, 80143 Napoli, Italy

Full list of author information is available at the end of the article
}

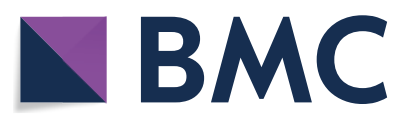

(c) The Author(s) 2021. This article is licensed under a Creative Commons Attribution 4.0 International License, which permits use, sharing, adaptation, distribution and reproduction in any medium or format, as long as you give appropriate credit to the original author(s) and the source, provide a link to the Creative Commons licence, and indicate if changes were made. The images or other third party material in this article are included in the article's Creative Commons licence, unless indicated otherwise in a credit line to the material. If material is not included in the article's Creative Commons licence and your intended use is not permitted by statutory regulation or exceeds the permitted use, you will need to obtain permission directly from the copyright holder. To view a copy of this licence, visit http://creativeco mmons.org/licenses/by/4.0/. The Creative Commons Public Domain Dedication waiver (http://creativecommons.org/publicdomain/ zero/1.0/) applies to the data made available in this article, unless otherwise stated in a credit line to the data. 
Keywords: Acne, Phase angle, Body composition, Bioelectrical impedance analysis (BIA), Mediterranean diet, Nutrition, Nutritionist

\section{Background}

Acne is a complex and a chronic inflammatory cutaneous disorder involving the pilosebaceous unit and its multifactorial pathogenesis is attributed to multiple factors such as hyperseborrhea, hyperkeratinization of the pilosebaceous duct, colonization of Propionibacterium acnes and perifollicular inflammation [1]. The influence of skin and gut microbioma in acne pathogenesis has also been investigated [2]. Its prevalence varies in overtime and different countries, and different lifestyles may influence it $[3,4]$. This skin disorder affects $70-80 \%$ of adolescents, persisting into the $20 \mathrm{~s}$ and $30 \mathrm{~s}$ in roughly 64 and $43 \%$ of individuals, respectively [5, 6]. Acne can leave lifelong scars and hyperpigmentations that need to be correctly prevented and treated $[7,8]$ considering that they impact considerably on patients' quality of life and emotional health [9]. The lesional pleomorphism is a typical aspect of patients with acne, represented by contemporary different lesions in the same patient, which can be both inflammatory lesions (papules, pustules, and nodules) and noninflammatory lesions such as comedones. In this context, acne may be present in a wide variety of clinical manifestations depending on the severity of the predominant lesion, number, and type [1]. The abnormal desquamation of sebaceous follicle epithelium (comedogenesis), sebaceous gland hyperplasia with seborrhea, increased bacterial colonization of the follicle (Propionibacterium acnes), and immunological and inflammatory factors, are the most notable pathophysiological factors that influence the development of acne are [10]. The immunochemical pathways linked to the state of inflammation in acne are complex and involves several inflammatory mediators and their target receptors, including cytokines, defensins, peptidases, sebum lipids, and neuropeptides [11]. In particular increased prostaglandin E2 and PPAR $\gamma$ levels can induce sebaceous gland hyperplasia and overshooting sebum production [12]. These sebum changes might induce inflammation leading to acne lesions. In addition, also Propionibacterium acnes has been shown to trigger pro-inflammatory cytokine release [12].

Beyond genetic factors, considered as the main cause in the development of acne, several evidence reported that commonly attribute the acne condition or its exacerbation also to hormonal influences and dietary factors $[13,14]$. Despite the scientific literature reporting contradictory result and conclusions on the role of diet in acne, due especially to the numerous limitations of study design, recently some well-designed, controlled, prospective studies have shown the relationship among specific nutrients and clinical severity of acne [13, 15-17]. Of interest, associations have been reported between cow's milk intake and consumption of high-glycaemic index foods with presence and longer acne duration [17]. Mediterranean diet (MD) is characterized by high consumption of extra virgin olive oil, fish, vegetables, legumes, whole-grain products, fruits, and nuts. Therefore, MD appears to be a low-glycaemic index diet and for this reason, it could be evaluated as a protective factor against acne development [17]. Of interest, MD as lifestyle, shows several benefits on different clinical inflammatory settings, including psoriasis [18, 19], hidradenitis suppurativa [20], polycystic ovary syndrome [21, 22], breast cancer [23-25], menopause [26, 27], and in all inflammatory and immune processes [28, 29]. MD decreases inflammation and oxidative stress, providing a significant source of antioxidant vitamins [30]. Nevertheless, to date, only few evidence reported the role of the MD on the development or exacerbation of acne [31].

In clinical practice, in addition to the evaluation of eating habits, the assessment of body composition has an important role. It is commonly measured by bioelectrical impedance analysis (BIA), a noninvasive, simple, and inexpensive method for the evaluation of body composition. BIA-device has a high agreement with Dual-energy $\mathrm{X}$-ray absorptiometry, the gold standard in the evaluation of body composition [32, 33]. Phase angle ( $\mathrm{PhA})$ is a BIAderived measure and that is associated with the inflammatory status in several diseases [34, 35]. In both healthy subjects and individuals with obesity, PhA has been validated as an easy tool to detect the inflammatory process [36-38]. PhA represents an excellent indicator of physical state, and cellular integrity, as well as of the water distribution between the extracellular (ECW) and intracellular water (ICW) compartments [39, 40]. Of interest, the PhA is an important prognostic index for monitoring the presence and evolution of chronic inflammatory processes [41]. Nevertheless, to the best of our knowledge, no studies to date have assessed PhA as a potential inflammatory marker in patients with acne.

Thus, considering the existence of inflammation in patients with acne, and while taking into account the well-known anti-inflammatory effects of MD, we suppose that patients with acne should be more prone to follow an unhealthy nutritional patter, lowly adherent to the MD, which contributes to worsening both inflammation and, 
consequently, the clinical severity of acne. Furthermore, since several studies demonstrated the role of $\mathrm{PhA}$, as an inflammatory state, we hypothesize to find this association also in patients with acne.

In this context, the main aim of the present study was to evaluate adherence to the MD and the body composition assessed by BIA and their association with the presence of acne and its clinical severity in a cohort of treatment-naïve patients with acne as compared with a control group of healthy individuals matched for gender, age, and BMI.

\section{Material and methods Design and setting}

This cross-sectional, case-control, observational study was carried out in patients with acne attending the Unit of Dermatology, Department of Clinical Medicine and Surgery, University Federico II of Naples (Italy), from January 2019 to February 2020. This study was carried out in accordance with the Code of Ethics of the World Medical Association (Declaration of Helsinki) for experiments involving humans, which has been approved by the Local Ethical Committee (no. 05/14). To the study participants, it was clearly explained the aim of this study and a written informed consent was obtained.

\section{Population study}

The study included 51 treatment-naïve patients affected by acne attending the Outpatient Clinic of the Unit of Dermatology in our Department. Fifty-one Caucasian healthy subjects (ascertained from medical history by an Endocrinologist), gender, age, and BMI matched were chosen as controls among hospital volunteers, employees from the same geographical area around Naples (Italy), or subjects who participated in the OPERA project (obesity, programs of nutrition, education, research and assessment of the best treatment) a Prevention Project held in Naples on 11-13 October 2019 [42]. The OPERA Prevention Project is also a strategic project of the UNESCO Chair on "Health Education and Sustainable Development" (https://www.unescochairnapoli.it/ for details).

All female subjects were evaluated in the follicular phase of the menstrual cycle and were not pregnant and non-lactating. A full medical history, including drug use, was collected.

Inclusion criteria for all groups were: individuals who were normal weight, overweight or with obesity, aged 18-42 years (women of childbearing age), lack of underlying metabolic disease (type 2 diabetes, hypertension, diagnosed anaemia, or any other metabolic disease requiring a special diet).

To increase the homogeneity of the subject samples, we included only patients with acne treatment-naïve and only adults of both genders with the following criteria of exclusion:

1. Age $<18$ years and $>43$ years;

2. Subjects with a diagnosis of acne lasting $>6$ months or were receiving any systemic treatment for acne including acitretin, ciclosporin, methotrexate, phototherapy or biologics for at least 3 months;

3. For females: menopause (defined as amenorrhea for $\geq 3$ years or amenorrhea for $\geq 1$ but $<3$ years and plasma follicle-stimulating hormone concentrations elevated to the postmenopausal range); pregnancy or lactation in the past 6 months;

4. Subjects with a self-reported history of recent weight change (>10\% weight change within the last 6 months);

5. Endocrine disorders that could affect body composition or nutritional status, such as hyperandrogenism and/or biochemical hyperandrogenaemia, oligomenorrhea due to polycystic ovarian syndrome or secondary aetiologies according to the Endocrine Society, including thyroid dysfunction, Cushing's syndrome, adrenal disorders, androgen-secreting tumors, congenital adrenal hyperplasia, and hyperprolactinaemia [43], altered thyroid hormone function tests or thyroid hormone treatment, and other chronic diseases that could interfere fluid homeostasis, such as liver or renal chronic diseases, cancer, acute or chronic inflammatory diseases, and presence of type 2 diabetes;

6. Use of medications that impact nutrients metabolism (oral contraceptive pills, metformin, anti-epileptics, anti-psychotics, statins, and fish oil), on body composition (drugs that could influence fluid balance, including nonsteroidal anti-inflammatory drugs, diuretics, laxative use), or weight-loss medications;

7. Hypocaloric diet or specific dietary regimens in the last three months, including vegan or vegetarian diets; supplementation with dietary supplements including antioxidants, vitamins, or minerals;

8. Individuals with implanted pacemakers or defibrillators because of the theoretical possibility of interference with the BIA-device activity due to the field of current induced by the impedance measurements.

\section{Sample size justification and power}

The calculation of the sample size was performed by considering two independent study groups, the effect size 0.95 with a type I error of 0.05 and a power of $95 \%$, as previously reported in other studies $[44,45]$. The number of subjects to be enrolled was found to be 50 per group that we decided to round up to 51 with a total of 
102 total subjects enrolled in the study to replace drop patients. The power was calculated by the differences of means \pm standard deviation (SD) of PREDIMED score in patients and control group $(5.59 \pm 2.89$ vs $10.67 \pm 1.78$, respectively). Considering the number of cases required in each group of 50, which were set at 51 for each group, a type I (alpha) error of 0.05 (95\%), and a type II (beta) of 0.05 , the calculated power size was $95 \%$. The calculation of sample size and power were performed using Sample Size Calculator Clinical Calc (https://clincalc.com/stats/ samplesize.aspx).

\section{Lifestyle habits}

Were defined as physically active, individuals habitually engaged in at least $30 \mathrm{~min} /$ day of aerobic exercise (YES/ $\mathrm{NO}$ ). We defined as former smokers were subjects who stopped smoking at least one year before the interview, current smokers subjects smoking at least one cigarette per day, and non-current smokers as the remaining participants; as we have already fully reported in previous studies [46-48]

\section{Anthropometric measurements}

The anthropometric measurements were performed by a certified clinical nutrition specialist with 5 years of experience in dietetics and nutrition, in the morning, between 8 and $10 \mathrm{am}$, after an overnight fast, according to the International Society for the Advancement of Kinanthropometry (ISAK 2006). All subjects dressed with light clothes without shoes during the assessment, as previously reported [49-52]. A calibrated balance beam scale (Seca 711; Seca, Hamburg, Germany) was used to assess weight, while a wall-mounted stadiometer (Seca 711; Seca, Hamburg, Germany) was used to measure height. After measuring weight and height, the BMI [weight $(\mathrm{kg})$ divided by height squared $\left.\left(\mathrm{m}^{2}\right), \mathrm{kg} / \mathrm{m}^{2}\right]$ was calculated.

According to World Health Organization WHO's criteria, we defined the participants as follows: BMI: $18.5-24.9 \mathrm{~kg} / \mathrm{m}^{2}$, normal-weight; BMI: $25.0-29.9 \mathrm{~kg} / \mathrm{m}^{2}$, overweight; BMI: $30.0-34.9 \mathrm{~kg} / \mathrm{m}^{2}$, grade I obesity; BMI: $35.0-39.9 \mathrm{~kg} / \mathrm{m}^{2}$, grade II obesity; BMI $\geq 40.0 \mathrm{~kg} / \mathrm{m}^{2}$, grade III obesity [53]. In according to the National Center for Health Statistics [54], using a non-stretchable measuring tape at the natural indentation or at a midway level between the lower edge of the rib cage and the iliac crest if no natural indentation was visible, the waist circumference was measured to the closest $0.1 \mathrm{~cm}$.

\section{Body composition}

Body composition was assessed using a BIA phase-sensitive system by a certified clinical nutrition specialist with 5 years of experience in the assessment of body composition with the BIA-method $(800-\mu \mathrm{A}$ current at a frequency single frequency of $50 \mathrm{kHz}$, BIA 101, RJL Akern Bioresearch, Florence, Italy) [55], as previously reported [56-58]. The BIA analysis was performed according to the European Society of Parental and Enteral Nutrition (ESPEN) [40]. Participants were asked to remove their shoes and socks and the contact areas with electrodes (BIATRODES Akern Srl; Florence-Italy) were scrubbed with alcohol immediately before their placement on the hand and the ipsilateral foot, according to Kushner [59]. $\mathrm{PhA}$ was obtained as the relationship between the resistance $(\mathrm{R})$ and reactance $(\mathrm{Xc})$, according to the following formula: $\mathrm{PhA}\left({ }^{\circ}\right.$, degrees $)=\mathrm{Xc} / \mathrm{R}^{*}(180 / \pi)$. $\mathrm{R}$ is mainly dependent on tissue hydration, while $\mathrm{Xc}$ is associated with cellularity, cell size, and integrity of the cell membrane $[60,61]$. BIA data were obtained under strictly standardized conditions; in particular, all participants had refrained from drinking, eating, and exercising for $6 \mathrm{~h}$ with no alcohol intake within $24 \mathrm{~h}$ before testing, were supine with limbs slightly spread apart from the body). The BIA-exam was performed by the same nutritionist and with the same device to avoid interobserver and interdevice variability. The BIA-tool was routinely checked with resistors and capacitors of known values, in particular the reliability for within-day and between-day measurements were $<1.6 \%$ for $\mathrm{R},<1.8 \%$ for $\mathrm{Xc}$, and $<1.9 \%$ for $\mathrm{R},<2.1 \%$ for $\mathrm{Xc}$, respectively. The coefficient of variation $(\mathrm{CV})$ of repeated measurements of $\mathrm{R}$ and $\mathrm{Xc}$ at $50 \mathrm{kHz}$ was assessed in 16 individuals (8 patients with acne and 8 controls): CVs were $1.4 \%$ for $\mathrm{R}$ and $1.5 \%$ for Xc.

\section{Adherence to the mediterranean diet}

Adherence to the MD was assessed using the validated PREDIMED questionnaire, consisting of 14 items [62]. PREDIMED questionnaire was administered by a qualified nutritionist during a face-to-face interview and had already been used in previous studies [63-65]. PREDIMED score was calculated by assigning a score of one and zero for each item, thus obtaining a total score ranging from zero to 14 points. Based on the PREDIMED score obtained, the participants were classified into three PREDIMED categories, as follows: $0-5$, low adherence to the MD; score 6-9, average adherence to the MD; and score $\geq 10$, high adherence to the MD [62].

\section{Classification and severity assessment of acne}

The dermatologists who evaluated the clinical severity of acne were blinded to the design of the study to prevent biases. Everyone had a complete dermatological examination including the GAGS, a quantitative scoring system to assess acne severity, first developed by Doshi et al. in 1997 [66]. The GAGS score is derived from the summation of six regional subscores. In detail, each point is 
derived by multiplying the factor for each region (the factor for chest and upper back is 3 , for chin and nose is 1 , and for forehead and each cheek is 2 ) by the most heavily weighted lesion within each region ( 4 for $\geq$ one nodule, 3 for $\geq$ one pustule, 2 for $\geq$ one papule, and 1 for $\geq$ one comedone). The regional factors were derived from the consideration of the density of pilosebaceous units and surface area and distribution. The severity was graded as three GAGS categories: patients with GAGS score 1-18 was defined as mild (where lesions include several noninflammatory comedones with less than inflammatory lesions); moderate GAGS score was from 19 to 30 (presence of many comedones, papules, pustules, but no nodules), and severe if GAGS score from 31 to 38 (presence of inflammatory nodules in addition to papules and pustules) [66, 67]. GAGS score was clinically evaluated by a single experienced dermatologist. To prevent rate biases, the dermatologists who evaluated the GAGS score were blinded to the design of the study.

\section{Statistical analysis}

Results were expressed as mean $\pm \mathrm{SD}$ and categorical variables are expressed as a percentage. The data distribution was evaluated by Kolmogorov-Smirnov test and the abnormal data (age, weight, PREDIMED score, and ECW) were normalized by logarithm. Skewed variables were back transformed for presentation in tables and figures. Differences between patients with acne and controls in body composition characteristics and PREDIMED scores were analyzed by Student's paired $t$-test. The Chi-square $\left(x^{2}\right)$ test was used to determine the significance of differences in the frequency distribution of dietary components included in the PREDIMED questionnaire and adherence to the MD. The differences among GAGS categories (mild, moderate, and severe acne) on age, anthropometric measurements, body composition characteristics, and PREDIMED score were analysed by between-group ANOVA test followed by the Bonferroni post hoc test. The correlations among GAGS with age, anthropometric measurements, BIAparameters in patients with acne were assessed with the Pearson $r$ correlation coefficients were estimated. Bivariate proportional odds ratio (OR) models, 95\% interval confidence (IC), $\mathrm{R}^{2}, p$-value, were performed to assess of GAGS score on the 14 food items included in the PREDIMED questionnaire. Two multiple regression analysis models (stepwise method), expressed as $R^{2}$, Beta $(\beta)$ and $t$, with GAGS score as a dependent variable to estimate the predictive value of anthropometric measurements, BIA-parameters assessed, and adherence to the MD in patients with acne. Two-receiver operator characteristic (ROC) curves analysis was carried out to identify sensitivity and specificity, area under the curve (AUC), and
CI, as well as cut-off values of PREDIMED score and $\mathrm{PhA}$ in detecting the predictive of the highest values of GAGS severity. Test AUC for ROC analysis was also calculated and we entered 0.747 for AUC ROC and 0.5 for null hypothesis values. An Alfa $\alpha$ level of 0.05 (type 1 error) and a $\beta$ level of 0.2 (type II error) were used as the cut-off values for statistical significance. Variables with a variance inflation factor $>10$ were excluded to avoid multicollinearity. Values $\leq 5 \%$ were considered statistically significant. Data were collected and analyzed using the MedCalc ${ }^{\circledR}$ package (Version 12.3.0 1993- 2012-Mariakerke, Belgium).

\section{Results}

In this case-control, a single center study evaluated 102 individuals; 51 patients with acne and 51 controls were matched for gender, age, and BMI. In particular, in patients with acne and control group, 38 (74.5\%) subjects were females, age was $23.5 \pm 5.9$ vs $24.5 \pm 3.9$ years, $p=0.280$; and BMI was $24.7 \pm 4.1$ vs $24.6 \pm 1.7 \mathrm{~kg} / \mathrm{m}^{2}$, $p=0.786$. Of interest, patients with acne had the highest waist circumference values compared to their counterpart $(79.1 \pm 10.1$ vs $73.1 \pm 9.1 \mathrm{~cm}, p=0.04)$. No differences were evident in lifestyle characteristics, particularly physical activity 12 subjects (23.5\%) vs 11 individuals (21.6\%); $\mathrm{X}^{2}=0.00, p=1.00$ and cigarette smoking habits 12 subjects $(23.5 \%)$ vs 17 individuals $(33.3 \%) ; \chi^{2}=0.77$, $p=0.379$; in patients with acne and control group, respectively.

In the patients with acne, the clinical severity of acne evaluated by GAGS was $22.08 \pm 9.12$, in particular, according to GAGS categories, 17 patients (33.3\%) had mild acne, 26 patients (51.0\%) showed moderate acne, and eight patients (15.7\%) presented severe acne. No gender difference was evident in GAGS score $(23.0 \pm 10.2$ vs $21.8 \pm 8.9, p=0.677$; in males and females, respectively).

The anthropometric characteristics and body composition parameters of the study population evaluated by BIA, were summarized in Table 1 . Significant difference values of all impedance parameters evaluated were found in patients with acne compared to controls. Of interest, patients with acne had the worst body composition parameters, in particular lower PhA $(p=0.003)$ and higher fat mass $(p=0.010)$ than controls.

Analyzing the frequency response of dietary items included in the PREDIMED questionnaire in detail, we found that the patients with acne consumed less vegetables $(p=0.026)$, fruits $(p=0.008)$, legumes $(p=0.041)$, fish $(p<0.001)$, and nuts $(p=0.003)$; and more soda drinks $(p=0.034)$, commercial sweets and confectionery $(p=0.021)$, as compared with control group (Table 2).

Figure 1 reported PREDIMED scores in patients with acne and controls. As showed, patients with acne 
Table 1 Body composition characteristics assessed by bioelectrical impedance analysis in patients with acne and control group

\begin{tabular}{lccr}
\hline Parameters & $\begin{array}{l}\text { Patients with acne } \\
\mathbf{n = 5 1}\end{array}$ & $\begin{array}{l}\text { Control group } \\
\mathbf{n = 5 1}\end{array}$ & $\boldsymbol{p}$-value* \\
\hline Weight $(\mathrm{kg})$ & $68.4 \pm 15.5$ & $72.6 \pm 4.1$ & 0.059 \\
R $(\Omega)$ & $539.3 \pm 78.3$ & $424.6 \pm 74.7$ & $<\mathbf{0 . 0 0 1}$ \\
XC $(\Omega)$ & $55.8 \pm 8.0$ & $46.9 \pm 8.4$ & $<\mathbf{0 . 0 0 1}$ \\
PhA $\left(^{\circ}\right)$ & $5.9 \pm 0.6$ & $6.3 \pm 0.6$ & $\mathbf{0 . 0 0 3}$ \\
TBW $(\mathrm{Lt})$ & $36.5 \pm 5.2$ & $44.4 \pm 5.1$ & $<\mathbf{0 . 0 0 1}$ \\
ICW $(\mathrm{Lt})$ & $19.7 \pm 2.8$ & $24.7 \pm 2.9$ & $<\mathbf{0 . 0 0 1}$ \\
ECW $(\mathrm{Lt})$ & $16.9 \pm 2.9$ & $19.7 \pm 2.5$ & $<\mathbf{0 . 0 0 1}$ \\
ECW/ICW ratio & $0.86 \pm 0.10$ & $0.80 \pm 0.1$ & $\mathbf{0 . 0 0 3}$ \\
FM (Kg) & $18.4 \pm 12.0$ & $13.4 \pm 5.8$ & $\mathbf{0 . 0 1 0}$ \\
FFM (Kg) & $49.9 \pm 7.1$ & $59.1 \pm 5.5$ & $<\mathbf{0 . 0 0 1}$ \\
BCM (Kg) & $25.1 \pm 5.2$ & $32.7 \pm 3.5$ & $<\mathbf{0 . 0 0 1}$ \\
\hline
\end{tabular}

Significant difference values of all impedance parameters evaluated were found in patients with acne compared to controls. Results are expressed as mean \pm SD. Weight and ECW were logarithmically normalized and transformed and backtransformed for presentation in table. Differences in the two groups were analysed by paired Student's $t$ test

$R$ Resistance, $X C$ reactance, $P h A$ phase angle, TBW total body water, ICW intracellular water, ECW extra-cellular water, $F M$ fat mass, FFM free fat mass, $B C M$ body cell mass

${ }^{*}$ A $p$ value in bold type denotes a significant difference $(p<0.05)$

presented the lowest adherence score to the Mediterranean diet compared to the control group $(p<0.001)$. In detail, patients with acne compared to the control group, showed the highest percentage of low adherence to the Mediterranean diet $\left(17.6 \%\right.$ vs $\left.0.0 \% ; \chi^{2}=7.80, p=0.005\right)$, and the lowest percentage of high adherence to the Mediterranean diet $\left(43.1 \%\right.$ vs $\left.72.5 \% ; x^{2}=7.88, p=0.004\right)$; no difference was evident for the average adherence to the Mediterranean diet $\left(39.2 \%\right.$ vs $\left.27.5 \% ; \chi^{2}=1.10, p=0.293\right)$.

Table 3 reports age, weight, BMI, waist circumference, and body composition characteristics assessed by BIA in patients with acne, across GAGS categories. In detail, stratifying the patients with acne according to GAGS categories, weight $(p=0.017)$, BMI $(p=0.002)$, waist circumference $(p=0.020)$, ECW $(p=0.050), \mathrm{ECW} / \mathrm{ICW}$ ratio $(p=0.007)$, and fat mass $(\mathrm{FM})(p=0.015)$ increased, while PhA decreased significantly $(p=0.006)$.

Likewise, dividing patients with acne according to GAGS categories, PREDIMED score decreased significantly along as the clinical severity of acne increases ( $p=0.007)$, Fig. 2 .

\section{Correlation analysis}

Correlations among age, anthropometric measurements, and body composition characteristics with GASG score in patients with acne were reported in Table 4. Significant correlations were found between GAGS score, weight and waist circumference $(p=0.002)$, and BMI $(p<0.001)$. In addition, GAGS score was also negatively associated with Xc $(p=0.035)$ and PhA $(p<0.001)$, and positively correlated with ECW $(p=0.008), \mathrm{ECW} / \mathrm{ICW}(p=0.001)$, and FM $(p=0.002)$; Table 4 .

Table 2 Response frequency of dietary components included in the PREDIMED questionnaire in patients with acne and control group

\begin{tabular}{|c|c|c|c|c|c|c|c|}
\hline \multirow[t]{2}{*}{ Questions of PREDIMED questionnaire } & \multicolumn{2}{|c|}{ Patients with acne } & \multicolumn{3}{|c|}{ Control group } & \multirow[b]{2}{*}{$x$} & \multirow[b]{2}{*}{$p$-value* } \\
\hline & $\mathbf{n}$ & $\%$ & $\mathbf{n}$ & & $\%$ & & \\
\hline Use of extra virgin olive oil as main culinary lipid & 48 & 94.1 & 44 & 86.3 & & 0.99 & 0.318 \\
\hline Extra virgin olive oil > 4 tablespoons & 42 & 82.4 & 42 & 82.4 & & 0.07 & 0.795 \\
\hline Vegetables $\geq 2$ servings/day & 25 & 49.0 & 37 & 72.5 & & 4.98 & 0.026 \\
\hline Fruits $\geq 3$ servings/day & 25 & 49.0 & 39 & 76.5 & & 7.09 & 0.008 \\
\hline Red/processed meats $<1 /$ day & 37 & 72.5 & 27 & 52.9 & & 3.39 & 0.065 \\
\hline Butter, cream, margarine $<1 /$ day & 39 & 76.5 & 45 & 88.2 & & 1.69 & 0.194 \\
\hline Soda drinks $<1 /$ day & 29 & 56.9 & 40 & 78.4 & & 4.48 & 0.034 \\
\hline Wine glasses $\geq 7 /$ week & 17 & 33.3 & 23 & 45.1 & & 1.03 & 0.311 \\
\hline Legumes $\geq 3 /$ week & 33 & 64.7 & 43 & 84.3 & & 4.18 & 0.041 \\
\hline Fish/seafood $\geq 3 /$ week & 23 & 45.1 & 45 & 88.2 & & 19.46 & $<0.001$ \\
\hline Commercial sweets and confectionery $\leq 2 /$ week & 33 & 64.7 & 44 & 86.3 & & 5.30 & 0.021 \\
\hline Tree nuts $\geq 3 /$ week & 22 & 43.1 & 38 & 74.5 & & 9.11 & 0.003 \\
\hline Poultry more than red meats & 36 & 70.6 & 45 & 88.2 & & 3.84 & 0.051 \\
\hline Use of sofrito sauce $\geq 2 /$ week & 29 & 56.9 & 32 & 62.7 & & 0.16 & 0.686 \\
\hline
\end{tabular}

Patients with acne consumed less vegetables, fruits, legumes, fish, and nuts; and more soda drinks, commercial sweets, and confectionery, as compared with the control group. Results are expressed as numbers and percentage. Differences in the frequency response of dietary components included in the PREDIMED questionnaire were analysed by Chi-square $\left(X^{2}\right)$ test

PREDIMED PREvención con DletaMEDiterránea

${ }^{*} \mathrm{~A} p$ value in bold type denotes a significant difference $(p<0.05)$ 


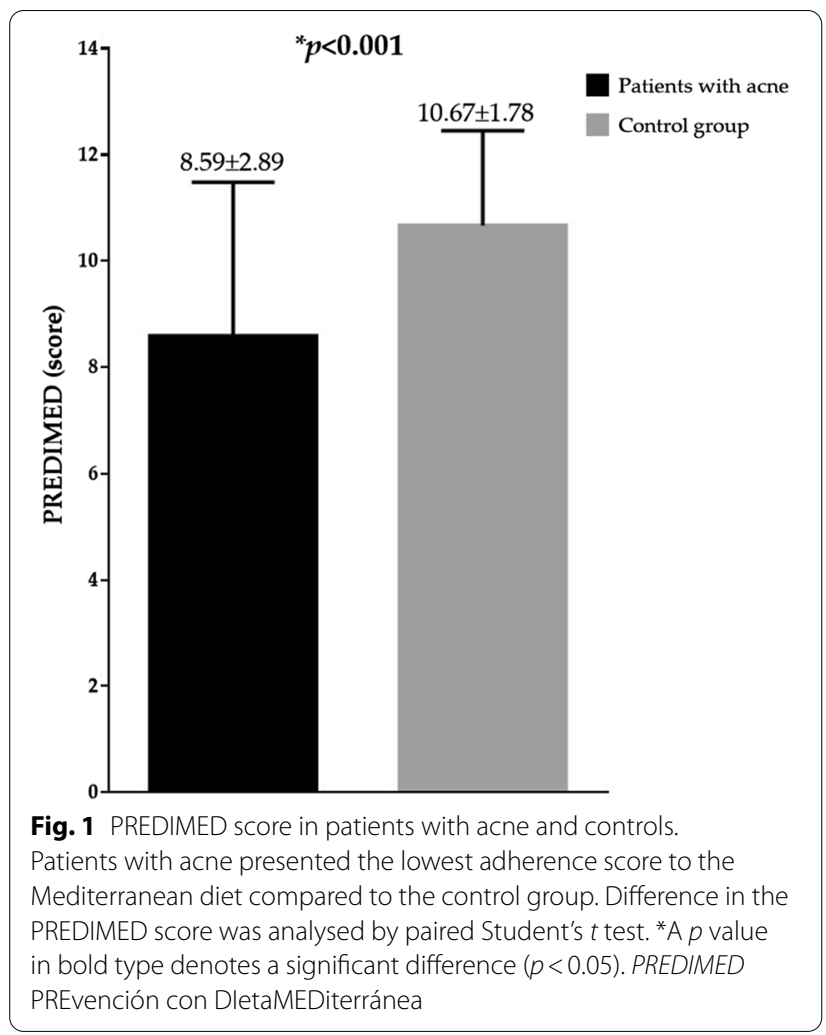

Bivariate proportional OR models were performed to assess the association of GAGS scores with the 14 food items included in the PREDIMED questionnaire. In particular, in this model, the lowest GAGS scores were significantly associated with the highest OR of consumption Mediterranean food items, including the use and quantity of extra virgin olive $(\mathrm{OR}=0.79, p=0.020$ and $\mathrm{OR}=0.89$, $p=0.025$; respectively), fruits $(\mathrm{OR}=0.88, p=0.003)$, legumes $(\mathrm{OR}=0.85, p=0.001)$, and fish $(\mathrm{OR}=0.84$, $p<0.001)$; Table 5 .

Figure 3 reported the negative correlation between GAGS score and PREDIMED score $(\mathrm{r}=-0.504$, $p<0.001)$ in patients with acne.

To compare the relative predictive power of anthropometric measurements, BIA-parameters assessed by $\mathrm{BIA}$, and adherence to the MD in patients with acne and associated with GAGS score, we performed two multiple regression analysis. The first model included anthropometric measurements, BIA-parameters, and PREDIMED scores. In this model, PREDIMED score was entered at the first step $(p<0.001)$, and the other variables were excluded from the analysis. Results were reported in Table 6. The second model included only BIA-parameters. In this model, PhA was entered at the first step $(p<0.001)$, and the other variables were excluded from the analysis; Table 6.

The first ROC analysis was performed to determine the cut-off values of PREDIMED score that was predictive of

Table 3 Age, anthropometric characteristics, and body composition characteristics were assessed by bioelectrical impedance analysis in patients with acne, across GAGS categories

\begin{tabular}{|c|c|c|c|c|}
\hline Parameters & $\begin{array}{l}\text { Mild acne } \\
n=17\end{array}$ & $\begin{array}{l}\text { Moderate acne } \\
n=26\end{array}$ & $\begin{array}{l}\text { Severe acne } \\
n=8\end{array}$ & ${ }^{*} p$-value \\
\hline Age (years) & $24.1 \pm 4.5$ & $23.5 \pm 6.2$ & $22.3 \pm 7.8$ & 0.780 \\
\hline Weight (kg) & $62.4 \pm 5.9$ & $68.6 \pm 15.4$ & $80.9 \pm 22.8$ & 0.017 \\
\hline BMI $\left(\mathrm{kg} / \mathrm{m}^{2}\right)$ & $22.8 \pm 1.5$ & $24.8 \pm 3.7$ & $28.8 \pm 5.9$ & 0.002 \\
\hline Waist circumference $(\mathrm{cm})$ & $74.8 \pm 4.9$ & $79.6 \pm 11.0$ & $86.5 \pm 11.3$ & 0.020 \\
\hline $\mathrm{R}(\Omega)$ & $526.9 \pm 73.6$ & $548.3 \pm 75.2$ & $536.6 \pm 102.6$ & 0.684 \\
\hline Xc $(\Omega)$ & $57.5 \pm 8.5$ & $56.2 \pm 6.3$ & $51.0 \pm 11.1$ & 0.163 \\
\hline $\operatorname{PhA}\left({ }^{\circ}\right)$ & $6.3 \pm 0.6$ & $5.9 \pm 0.5$ & $5.4 \pm 0.6$ & 0.006 \\
\hline TBW (Lt) & $35.9 \pm 3.9$ & $36.2 \pm 5.4$ & $38.9 \pm 6.9$ & 0.386 \\
\hline ICW (Lt) & $19.9 \pm 2.6$ & $19.5 \pm 2.9$ & $19.9 \pm 3.0$ & 0.867 \\
\hline $\mathrm{ECW}(\mathrm{Lt})$ & $16.1 \pm 1.8$ & $16.8 \pm 2.8$ & $19.0 \pm 4.1$ & 0.050 \\
\hline ECW/ICW ratio & $0.81 \pm 0.08$ & $0.86 \pm 0.09$ & $0.95 \pm 0.11$ & 0.007 \\
\hline $\mathrm{FM}(\mathrm{Kg})$ & $13.2 \pm 5.2$ & $18.9 \pm 10.6$ & $22.8 \pm 19.9$ & 0.015 \\
\hline FFM (Kg) & $49.1 \pm 5.4$ & $49.6 \pm 7.3$ & $53.1 \pm 9.4$ & 0.392 \\
\hline $\mathrm{BCM}(\mathrm{Kg})$ & $26.6 \pm 4.8$ & $24.6 \pm 5.2$ & $23.3 \pm 5.9$ & 0.261 \\
\hline
\end{tabular}

Stratifying patients with acne according to GAGS categories, weight, BMI, waist circumference, ECW, ECW/ICW ratio, and FM increased, while PhA decreased significantly. Results are expressed as mean \pm SD. Weight and ECW were logarithmically normalized and transformed and back-transformed for presentation in table. Differences in the three groups were analysed by ANOVA test, with the Bonferroni test as post-hoc test. * $\mathrm{A} p$ value in bold type denotes a significant difference $(p<0.05)$

$B M I$ body mass index, $R$ resistance, $X C$, reactance, $P h A$, phase angle, $T B W$ total body water, ICW intra-cellular water, ECW extra-cellular water, $F M$ fat mass, $F F M$ free fat mass, $B C M$ body cell mass 


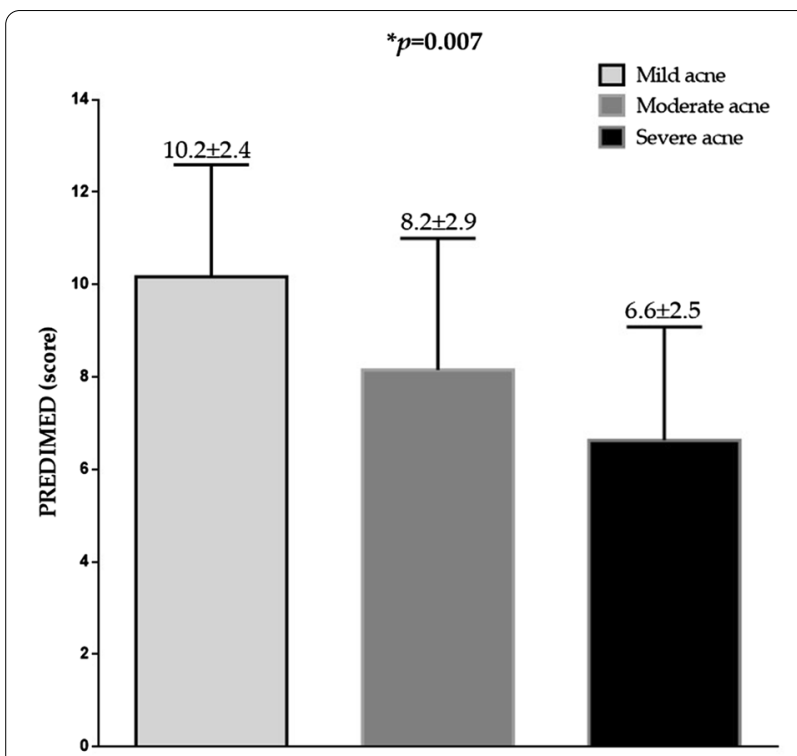

Fig. 2 PREDIMED scores in patients with acne according to GAGS categories. PREDIMED score decreased significantly along as the clinical severity of acne increases. Differences in the three groups were analysed by ANOVA test, with the Bonferroni test as post-hoc test. ${ }^{*} A p$ value in bold type denotes a significant difference $(p<0.05)$. PREDIMED PREvención con DletaMEDiterránea

Table 4 Correlations among age, anthropometric measurements, and body composition parameters in patients with acne

\begin{tabular}{llc}
\hline Patients with acne $(\mathbf{n}=\mathbf{5 1})$ & & \\
\hline Parameters & $\mathbf{r}$ & ${ }^{*} \boldsymbol{p}$-value \\
\hline Age (years) & -0.157 & 0.271 \\
Weight $(\mathrm{kg})$ & 0.432 & $\mathbf{0 . 0 0 2}$ \\
BMI $\left(\mathrm{Kg} / \mathrm{m}^{2}\right)$ & 0.522 & $<\mathbf{0 . 0 0 1}$ \\
Waist circumference $(\mathrm{cm})$ & 0.432 & $\mathbf{0 . 0 0 2}$ \\
R $(\Omega)$ & 0.060 & 0.678 \\
XC $(\Omega)$ & -0.296 & $\mathbf{0 . 0 3 5}$ \\
PhA $\left(^{\circ}\right)$ & -0.478 & $<\mathbf{0 . 0 0 1}$ \\
TBW (Lt) & 0.211 & 0.138 \\
ICW $(\mathrm{Lt})$ & 0.014 & 0.924 \\
ECW $(\mathrm{Lt})$ & 0.368 & $\mathbf{0 . 0 0 8}$ \\
ECW/ICW ratio & 0.464 & $\mathbf{0 . 0 0 1}$ \\
FM (Kg) & 0.427 & $\mathbf{0 . 0 0 2}$ \\
FFM (Kg) & 0.220 & 0.122 \\
BCM (Kg) & -0.233 & 0.100 \\
\hline
\end{tabular}

GAGS score was correlated with weight, waist circumference, $\mathrm{BMI}, \mathrm{Xc}, \mathrm{PhA}$, ECW ECW/ICW, and FM. Weight and ECW were logarithmically normalized and transformed and back transformed for presentation in table. Correlations between variables were performed using Pearson $r$ correlation coefficients

$B M I$ body mass index, $R$ resistance, $X C$ reactance, $P h A$ phase angle, TBW total body water, ICW intra-cellular water, ECW extra-cellular water, FM fat mass, FFM free fat mass, $B C M$ body cell mass

${ }^{*} \mathrm{~A} p$ value in bold type denotes a significant difference $(p<0.05)$ the highest value of GAGS severity (Fig. 4), while the second ROC analysis was performed to evaluate the cut-off value of $\mathrm{PhA}$ that was predictive of the highest value of GAGS severity (Fig. 5).

The threshold values of adherence to the MD predicting the highest GAGS severity were found at PREDIMED score $\leq 9(p=0.001$, AUC 0.747, standard error 0.076, 95\% CI 0.598 to 0.896; Fig. 4), in patients with acne. A value of $\mathrm{PhA}$ of $\leq 6.1^{\circ} \quad(p=0.003$, AUC 0.719 , standard error $0.075,95 \%$ CI 0.571 to 0.867 ) could serve as a threshold for a significantly increased risk of high value of GAGS severity.

\section{Discussion}

In our study, patients with acne showed a lower adherence to the MD, smaller PhA, and higher waist circumference compared to the control group matched for gender, age, and BMI. In addition, the assessment of body composition by BIA showed a different water distribution in patients with acne compared to controls, in particular a lower total body water and body cell mass, and a higher $\mathrm{ECW} / \mathrm{ICW}$ ratio and FM. The stratification of patients with acne in according to GAGS scores across GAGS categories allowed us to report a novel difference in PhA and PREDIMED scores across different GAGS categories with lower values in severe acne compared to moderate/ mild acne. As expected, BMI and waist circumference were the highest in patients with acne with the highest grades of GAGS (severe). To date, to the best of our knowledge, this is the first study investigating nutritional status in the relationship between body composition and adherence to the MD in a sample of an adult population with acne across GAGS categories. Of interest, the most important result of the present study is the negative correlation between PhA and GAGS score. In the multiple regression analysis, PREDIMED score was the major determinant of anthropometric measurements, BIAparameters, and adherence to the $\mathrm{MD}$, and $\mathrm{PhA}$ was the major determinant of anthropometric measurements and BIA-parameters. Finally, based on the ROC curve analysis, the most sensitive and specific cut-offs for the PREDIMED score and PhA to predict the highest GAGS score were $\leq 9$ and $\leq 6.1^{\circ}$, respectively. To date, this is the first study reporting the specific cut-offs of adherence to the $\mathrm{MD}$ and PhA which predict the clinical severity of acne.

$\mathrm{PhA}$ is an electrical parameter obtained directly from the BIA that has been used as an indicator of cell membrane function and as a marker of nutritional status in different populations [36]. In detail, whereas high $\mathrm{PhA}$ suggest a large number of intact cell membranes [36], low PhA are considered a marker for decreased cell membrane integrity or related to cell death [68]. Cell membrane integrity disarrangements, consequently of 
Table 5 Bivariate proportional OR model to assess the association between GAGS score and food items included in the PREDIMED questionnaire

\begin{tabular}{|c|c|c|c|c|}
\hline \multirow[b]{2}{*}{ Questions } & \multicolumn{4}{|c|}{ Patients with acne $(n=51)$} \\
\hline & OR & $p$ value & $95 \%$ IC & $\mathrm{R}^{2}$ \\
\hline Use of extra virgin olive oil as main culinary lipid & 0.79 & 0.020 & $0.63-1.01$ & 0.12 \\
\hline Extra virgin olive oil $>4$ tablespoons & 0.89 & 0.025 & $0.81-0.99$ & 0.11 \\
\hline Vegetables $\geq 2$ servings/day & 0.96 & 0.151 & $0.89-1.02$ & 0.04 \\
\hline Fruits $\geq 3$ servings/day & 0.88 & 0.003 & $0.82-0.96$ & 0.21 \\
\hline Red/processed meats $<1 /$ day & 0.96 & 0.206 & $0.89-1.03$ & 0.03 \\
\hline Butter, cream, margarine $<1 /$ day & 0.98 & 0.634 & $0.91-1.06$ & 0.01 \\
\hline Soda drinks $<1 /$ day & 1.00 & 0.993 & $0.94-1.06$ & 0.01 \\
\hline Wine glasses $\geq 7 /$ week & 0.95 & 0.102 & $0.88-1.01$ & 0.06 \\
\hline Legumes $\geq 3 /$ week & 0.85 & 0.001 & $0.76-0.94$ & 0.27 \\
\hline Fish/seafood $\geq 3 /$ week & 0.84 & $<0.001$ & $0.75-0.93$ & 0.32 \\
\hline Commercial sweets and confectionery $\leq 2 /$ week & 0.99 & 0.933 & $0.93-1.06$ & 0.01 \\
\hline Tree nuts $\geq 3 /$ week & 0.95 & 0.134 & $0.89-1.02$ & 0.05 \\
\hline Poultry more than red meats & 1.02 & 0.515 & $0.96-1.09$ & 0.01 \\
\hline Use of sofrito sauce $\geq 2 /$ week & 0.96 & 0.236 & $0.90-1.03$ & 0.03 \\
\hline
\end{tabular}

The lowest GAGS scores were significantly associated with the highest OR of consumption some Mediterranean food items, including the use and quantity of extra virgin olive, fruits, legumes, and fish. Bivariate proportional OR model, $95 \%$ IC, and $\mathrm{R}^{2}$

GAGS Global Acne Grading System, PREDIMED PREvención con Dleta MEDiterránea, OR odds ratio, IC interval confidence

${ }^{*} \mathrm{~A} p$ value in bold type denotes a significant difference $(p<0.05)$

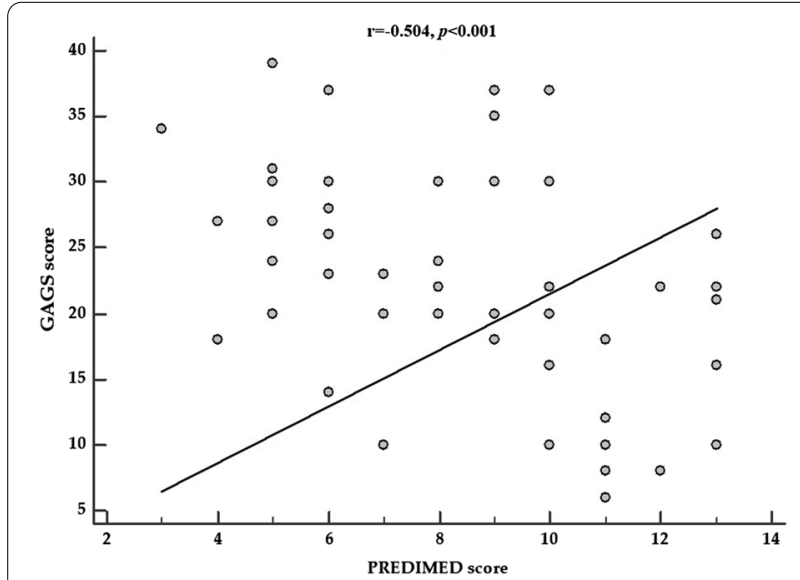

Fig. 3 The correlation between GAGS score and PREDIMED score in patients with acne. GAGS score showed a negative association with PREDIMED score $(r=-0.504, p<0.001)$ as shown in the figure. Correlations between two variables were performed using Pearson $r$ correlation coefficients. ${ }^{*} A$ p value in bold type denotes a significant difference $(p<0.05)$. GAGS global acne grading system, PREDIMED PREvención con Dleta MEDiterránea

tissue injury, are a well-known condition related to the inflammatory status [69]. It is interesting to note how, in different clinical settings, including psoriasis $[18,70]$, hidradenitis suppurativa [20], obesity [71], and polycystic ovary syndrome [21], showed a strong relationship between $\mathrm{PhA}$ and inflammatory markers, including
Table 6 Multiple regression analysis models (stepwise method) with the GAGS score as a dependent variable to estimate the predictive value of anthropometric measurements, BIAparameters assessed, and adherence to the MD in patients with acne

\begin{tabular}{lllll}
\hline Parameters & \multicolumn{4}{l}{ Multiple regression analysis } \\
\cline { 2 - 5 } & $\mathbf{R}^{\mathbf{2}}$ & $\boldsymbol{\beta}$ & $\mathbf{t}$ & $\boldsymbol{p}$ value* \\
\hline $\begin{array}{l}\text { Model 1 } \\
\text { PREDIMED score }\end{array}$ & 0.239 & -0.504 & -4.09 & $<\mathbf{0 . 0 0 1}$ \\
$\begin{array}{l}\text { Model 2 } \\
\text { PhA }\left(^{\circ}\right)\end{array}$ & 0.213 & -0.478 & -3.81 & $<\mathbf{0 . 0 0 1}$ \\
\hline
\end{tabular}

In the first model included anthropometric measurements, BIA-parameters, and PREDIMED score, PREDIMED score entered at the first step. In the second model including only BIA-parameters, PhA was entered at the first step GAGS Global Acne Grading System, PREDIMED PREvención con Dleta MEDiterránea, PhA phase angle

${ }^{*} \mathrm{~A} p$ value in bold type denotes a significant difference $(p<0.05)$

C-reactive protein $[34,72]$. Our results demonstrated that in our group of patients with acne, an inflammatory skin disease, $\mathrm{PhA}$ values were significant lower unlike healthy subjects, matched for gender, age, and BMI, known cofactors that influence PhA. This let us to speculate that PhA, a known inflammatory parameter in several skin diseases $[20,70]$, could represent also a possible biomarker to quantify inflammation in subjects with acne, a chronic inflammation of the folliculo-pilosebaceous 


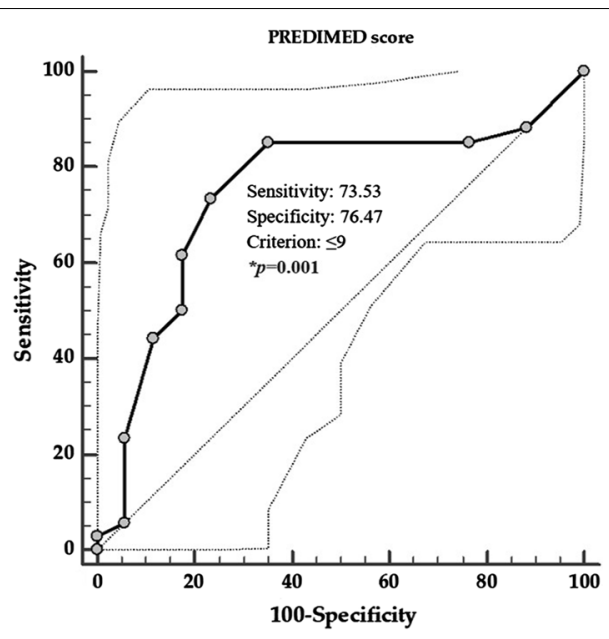

Fig. 4 ROC for the value of PREDIMED score predictive of the highest GAGS severity. In the ROC analysis, the threshold value of PREDIMED scores predicting the highest GAGS severity were found at $\leq 9$. ${ }^{*}$ A $p$ value in bold type denotes a significant difference $(p<0.05)$. GAGS global acne grading system, PREDIMED PREvención con Dleta MEDiterránea

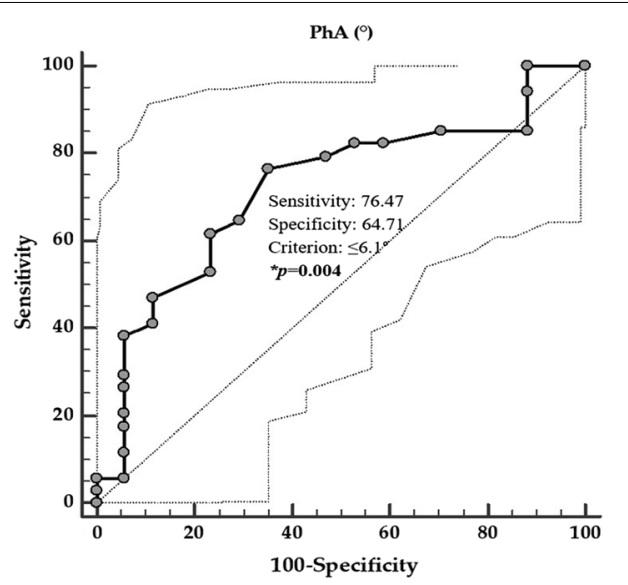

Fig. 5 ROC for the value of PhA predictive highest GAGS severity. In the ROC analysis, the threshold value of PhA predicting the highest GAGS severity were found at $\leq 6.1^{\circ}$. $A p$ value in bold type denotes a significant difference $(p<0.05)$. PhA phase angle, GAGS global acne grading system

unit. Although in our study we have not evaluated specific inflammatory biomarkers, including C-reactive protein, this conclusion remains only speculative. Therefore, although our results cannot demonstrate a causal link, they suggest that $\mathrm{PhA}$ could be a marker of inflammation in patients with acne and $\mathrm{PhA} \leq 6.1^{\circ}$ predict the highest GAGS score.

Acne vulgaris is a common inflammatory disease of the pilosebaceous units of the skin, with a multifactorial and complex pathogenesis [1]. In a recent review on the role of diet on acne and its response to treatment, Baldwin $\mathrm{H}$. et al., [17] found that in several evidence beyond the role of genetics, acne is considered due primarily to environmental factors and specific foods and dietary patterns have been included as possible triggers. Low-glycaemic index foods can influence the clinical severity of acne due to their positive influence on the reduction of seborrhea and keratinocytes turnover. Several evidence confirm the role of high-glycaemic index foods on the pathogenesis of acne. Hyperinsulinemia caused by the consumption of foods with a high glycemic index, increased insulinlike growth factor 1 levels, with consequent reduction of insulin-like growth factor-binding protein 3 and proliferation of basal keratinocytes thus leading to dysregulation of normal corneocytic apoptosis [73]. The first step in the formation of microcomedone is the acroinfundibular hyperkeratinization [74]. The main foods with a low glycemic index are legumes and fruit [75]. Our data report that acne patients consume fewer weekly servings of fruit and legumes than the non-acne group. Furthermore, the reduced consumption of these two Mediterranean foods were associated with worse clinical acne severity.

Moreover, foods high in omega 3 leading to a lower omega6/omega3 ratio due to their anti-inflammatory action are among the most possible causes of the reduction of the clinical severity of acne [76]. The higher omega6/omega3 ratio, characteristic of Western diet (poor in the consumption of fish, fresh vegetables, and legumes) is considered crucial in all inflammatory states, including [76, 77]. Of interest, in non-industrialized countries, the omega6/omega 3 ratio is usually around $2-3: 1$, in reverse, in industrialized countries, such as USA, this ratio is close to $10: 1$; this could at least partially explain the difference in acne epidemiology $[76,78]$. The main source of omega 3 in our diet is represented by the consumption of fish. Fish consumption has been reported to be associated with the clinical severity of acne [79]. In particular, Rietkerk and Woolf showed that patients with moderate and severe acne consumed fewer portions of fish than those with mild or no acne [80]. Likewise, Di Landro et al. [3], reported that fish consumption was associated with a protective effect on acne risk. Similar to these studies, our results demonstrated that patients with acne consumed fewer weeks fish servings than controls, and fish intake was negatively associated with the clinical severity of acne. The omega- 3 fatty acids found in fish and the high fiber content in fruits and vegetables, could explain these observed protective effects from the consumption of these Mediterranean foods, which have been reported to lower the insulin-like growth factor 1 levels, thus reducing acne risk [17]. In addition, a high content of hormones active in the milk could act either on insulin 
levels leading to infundibular hyperkeratinization or that on pilosebaceous follicles (5- $\alpha$-androstenedione and 5 - $\alpha$-pregnanedione), thus leading to worsening of acne $[17,81]$. However, in the relationship between acne with single foods, it should be kept in mind that the diet is a complex combination of foods and nutrients. Thus, it is challenging to separate the effect of a single nutrient (eg omega 3, fiber, etc.) or food group (e.g. fish and legumes) from that of others in free-living populations [82], and it would therefore be more correct to evaluate the effects of an entire dietary pattern with respect to a single nutrient or food. In this context, beyond weight loss, a higher adherence to the MD has been reported to have a wellestablished anti-inflammatory activity, which is mainly due to the high intake of both polyunsaturated fatty acids omega 3 and antioxidants contained in extra-virgin olive oil, vegetables, fruits, and wine [83], and the microbiotaderived production of short chain fatty acids that are induced by dietary fiber [84].

However, only one study evaluated adherence to the MD with the clinical severity of acne [31]. In particular, in 2012, Skroza et al., in a community-based case-control study in 93 patients with acne and 200 controls affirmed that the MD score $\geq 6$ revealed a protective effect towards acne [31]. This was the first study reporting a protective role of the MD in the pathogenesis of acne.

In our study population, the MD score was evaluated by PREDIMED score, which revealed that acne patients followed a dietary regimen farther from the MD than the one followed by healthy controls. Acne patients ate less Mediterranean foods than healthy controls. MD is richer in fruit, vegetables, and integral foods that could be protective for their both inflammatory and antioxidants properties [31]. The catalase and superoxide dismutase levels with increased oxidative stress, playing an important role in the pathogenesis of acne [85]. MD is a well-established health-promoting dietary pattern. There is evidence that high adherence to the MD is negatively correlated with insulin resistance [86], adiposity [87], inflammation and immune system function $[28,29]$, gut microbiota [88], and endocrine dysfunction [89], all conditions associated with acne [17]. Although our results cannot demonstrate a causal link, they suggest that high adherence to the MD could be a marker of inflammation in patients with acne and the PREDIMED score $\leq 9$ predicted the highest GAGS score. On this basis, it is conceivable that a high adherence to the MD might be considered one of the best nutritional strategies for the management of patients with acne.

Some limitations should be reported in the present study. First, being a cross-sectional study, the cause-effect association between PhA, PREDIMED score and clinical severity of acne cannot be determined. Likewise, the design of this study did not draw a final conclusion on the prognostic value of $\mathrm{PhA}$ and degree of adherence to the $\mathrm{MD}$ in the prediction of clinical severity of acne.

Second, the possible underlying inflammatory linking PhA and PREDIMED score with the clinical severity of acne should be better investigated by measuring serum inflammatory biomarkers, such as c-reactive protein levels and IL-6; thus, our hypothesis of a beneficial effect of both high PhA and high adherence to the MD on the clinical severity of acne remains largely speculative. However, we point out that this was the first study reporting in patients with acne the negative correlation among $\mathrm{PhA}$ values and PREDIMED score with clinical severity of acne.

Third, the sample size was relatively small. Nevertheless, we have calculated the sample size calculated by the differences of means of PREDIMED score in patients with acne and controls, using 95\% statistical power. Furthermore, patients and controls shared the same geographical area, being a monocentric study, therefore both groups had likely similar food availability and dietary consumption patterns, and this allowed to improve the homogeneity of the study population.

Fourth, the proposed cut-off points of PhA and PREDIMED score for identifying the highest clinical severity of acne should be used with caution until an appropriate cross-validation will be performed and the data of clinical evidence in larger population samples will be made available.

A strong point of our research with the aim of minimizing interoperator variability is that only the very same expert nutritionist performed and interpreted BIAparameters, anthropometric measurements, and PREDIMED questionnaires. In addition, the diagnosis of acne that was clinically evaluated by dermatologists and not self-reported.

An additional strong point is that we included only naive treatment patients and both acne patients and matched controls have been well characterized.

In addition, although we based the statistical analysis and results mostly on raw BIA measurements (as PhA) rather than BIA volumetric parameters, the evaluation of FM, FFM, and body cell mass were not validated by gold standard reference methods, such as dual-X ray absorptiometry. For this reason, it is essential that expert nutritionists are mandatory for execution and especially for the interpretation of BIA measurements, in particular PhA.

Finally, adherence to the MD has been adequately assessed by the PREDIMED questionnaire, the gold standard among adherence to the MD questionnaires [90]. PREDIMED questionnaire, less time-demanding of compilation, is less expensive, and requires less 
collaboration from subjects than other more comprehensive methods, such as the full-length food questionnaire [62]. Of interest, PREDIMED questionnaire allows one to provide feedback to the subjects immediately after the interview is completed. Moreover, to minimize any bias related to the filling of the questionnaire and to avoid the interoperator variability, PREDIMED questionnaire was face-to-face administered and not self-reported.

\section{Conclusion}

In summary, in the present cross-sectional, case-control, observational study, we reported for the first time: (i) smaller PhAs and low adherence to the MD in patients with acne compared to the control group matched for gender, age and BMI; (ii) direct associations among $\mathrm{PhA}$ and PREDIMED score with clinical severity of acne evaluated with GAGS score, suggesting the use of both PhA and PREDIMED score as a simple and inexpensive markers for both the clinical severity of acne and chronic inflammation. In addition, these data could support a therapeutic role of the Mediterranean dietary pattern in patients with acne, by contributing to reduce the inflammatory status that paves the way for an increase of clinical severity of acne. As possible translational applications, these results suggest that specific cut-off values for the PhA and PREDIMED score, contributing to identify patients with higher clinical severity of acne and could therefore be included as an auxiliary tool in the complex dermatological evaluation of the clinical severity of acne, and identifying those patients who could get an additional benefit from careful dietary interventions. In conclusion, our findings highlight the importance of nutritional assessment by a qualified nutritionist in patients with acne, not only for providing nutritional advices but also to identify subjects in which further performing clinical assessments.

\begin{abstract}
Abbreviations
PhA: Phase angle; BIA: Bioelectrical impedance analysis; MD: Mediterranean diet; PREDIMED: PREvención con Dleta MEDiterránea; GAGS: Global acne grading system; ECW: Extracellular water; ICW: Intracellular water; SD: Standard deviation; R: Resistance; Xc: Reactance; CV: Coefficient of variation; OR: Odds ratio; IC: Interval confidence; ROC: Receiver operator characteristic; AUC: Area under the curve.
\end{abstract}

\section{Acknowledgements}

We are thankful to Panta Rei Impresa Sociale srl (https://www.panta-rei.eu/ pantarei/) and Pasquale Antonio Riccio, for their scientific support.

\section{Authors' contributions}

Substantial contributions to the conception or design of the work: LB, SC and $\mathrm{MD}$; the acquisition, analysis, or interpretation of data for the work: GM, SS, AC, GF; Drafting the work or revising it critically for important intellectual content: LB, SC, MD, SS, LDG, CB, AC, GM and GF; final approval of the version to be published: LB and GF; agreement to be accountable for all aspects of the work in ensuring that questions related to the accuracy or integrity of any part of the work are appropriately investigated and resolved: LB, SC, MD, SS, AC, GM and GF. All authors read and approved the final manuscript.

\section{Funding}

This research received no external funding.

\section{Availability of data and materials}

All data generated or analyzed during this study are included in this published article.

\section{Declarations}

\section{Ethics approval and consent to participate}

The study was conducted in full agreement with the national and international regulations and the Declaration of Helsinki (2000). All participants were fully informed about the study requirements and were required to accept the data sharing and privacy policy before participating in the study.

\section{Consent for publication}

Not applicable.

\section{Competing interests}

None of the authors have conflicts of interest to declare.

\section{Author details}

${ }^{1}$ Dipartimento di Scienze Umanistiche, Centro Direzionale, Università Telematica Pegaso, Via Porzio, isola F2, 80143 Napoli, Italy. ${ }^{2}$ Endocrinology Unit, Department of Clinical Medicine and Surgery, Centro Italiano per la cura e il Benessere del paziente con Obesità (C.I.B.O), University Medical School of Naples, Via Sergio Pansini 5, 80131 Naples, Italy. ${ }^{3}$ Section of Dermatology, Department of Clinical Medicine and Surgery, University of Naples Federico II, Naples, Italy. ${ }^{4}$ Unit of Endocrinology, Dipartimento di Medicina Clinica e Chirurgia, Federico II University Medical School of Naples, Via Sergio Pansini 5, 80131 Naples, Italy. ${ }^{5}$ Cattedra Unesco "Educazione alla salute e allo sviluppo sostenibile", University Federico II, Naples, Italy.

Received: 12 February 2021 Accepted: 9 April 2021

Published online: 26 April 2021

\section{References}

1. Zaenglein AL. Acne vulgaris. N Engl J Med. 2018;379(14):1343-52. https:// doi.org/10.1056/NEJMcp1702493.

2. Balato A, Cacciapuoti S, Di Caprio R, Marasca C, Masarà A, Raimondo A, et al. Human microbiome: composition and role in inflammatory skin disease. Arch Immunol Ther Exp (Warsz). 2019;67(1):1-18. https://doi.org/ 10.1007/s00005-018-0528-4.

3. Di Landro A, Cazzaniga S, Parazzini F, Ingordo V, Cusano F, Atzori L, et al. Family history, body mass index, selected dietary factors, menstrual history, and risk of moderate to severe acne in adolescents and young adults. J Am Acad Dermatol. 2012;67(6):1129-35. https://doi.org/10. 1016/j.jaad.2012.02.018

4. Ballanger F, Baudry P, N'Guyen JM, Khammari A, Dréno B. Heredity: a prognostic factor for acne. Dermatology. 2006;212(2):145-9. https://doi. org/10.1159/000090655.

5. Bagatin E, Timpano DL, Guadanhim dos LRS, Nogueira VMA, Terzian LR, Steiner $D$, et al. Acne vulgaris: prevalence and clinical forms in adolescents from São Paulo, Brazil. An Bras Dermatol. 2014;89(3):428-35. https:// doi.org/10.1590/abd1806-4841.20142100.

6. Fabbrocini G, Izzo R, Donnarumma M, Marasca C, Monfrecola G. Acne smart club: an educational program for patients with acne. Dermatology. 2014;229(2):136-40. https://doi.org/10.1159/000,362,809.

7. Fabbrocini G, Cacciapuoti S. Evaluation, prevention, and management of acne scars: issues, strategies, and enhanced outcomes. J Drugs Dermatol. 2018;17(12):s44-48.

8. Aktan S, Ozmen E, Sanli B. Anxiety, depression, and nature of acne vulgaris in adolescents. Int J Dermatol. 2000;39(5):354-7. https://doi.org/10. 1046/j.1365-4362.2000.00907.x. 
9. Fabbrocini G, Cacciapuoti S, Monfrecola G. A qualitative investigation of the impact of acne on health-related quality of life (HRQL): development of a conceptual model. Dermatol Ther (Heidelb). 2018;8(1):85-99. https:// doi.org/10.1007/s13555-018-0224-7.

10. Bernales SA. Acne vulgaris: role of the immune system. $\mathrm{Br} J$ Dermatol. 2019;181(6):1226-37. https://doi.org/10.1111/bjd.17851.

11. Tanghetti EA. The role of inflammation in the pathology of acne. J Clin Aesthet Dermatol. 2013;6(9):27-35.

12. Zouboulis CC. Endocrinology and immunology of acne: two sides of the same coin. Exp Dermatol. 2020;29(9):840-59. https://doi.org/10.1111/exd. 14172.

13. Dalloglio F, Nasca MR, Fiorentini F, Micali G. Diet and acne: review of the evidence from 2009 to 2020. Int J Dermatol. 2021. https://doi.org/10. 1111/ijd.15390 (Online ahead of print).

14. Fabbrocini G, Izzo R, Faggiano A, Del Prete M, Donnarumma M, Marasca C, et al. Low glycaemic diet and metformin therapy: a new approach in male subjects with acne resistant to common treatments. Clin Exp Dermatol. 2016;41(1):38-42. https://doi.org/10.1111/ced.12673.

15. Fiedler F, Stangl Gl, Fiedler E, Taube K-M. Acne and nutrition: a systematic review. Acta Derm Venereol. 2017;97(1):7-9. https://doi.org/10.2340/ 00015555-2450.

16. Claudel JP, Auffret N, Leccia MT, Poli F, Dréno B. Acne and nutrition: hypotheses, myths and facts. J Eur Acad Dermatol Venereol. 2018;32(10):1631-7. https://doi.org/10.1111/jdv.14998.

17. Baldwin $\mathrm{H}$, Tan J. Effects of diet on acne and its response to treatment. Am J Clin Dermatol. 2021;22(1):55-65. https://doi.org/10.1007/ s40257-020-00542-y.

18. Barrea L, Nappi F, Di Somma C, Savanelli MC, Falco A, Balato A, et al. Environmental risk factors in psoriasis: the point of view of the nutritionist. Int J Environ Res Public Health. 2016;13(5):743. https://doi.org/10.3390/ijerp h13070743.

19. Barrea L, Balato N, Di Somma C, Macchia PE, Napolitano M, Savanelli MC, et al. Nutrition and psoriasis: is there any association between the severity of the disease and adherence to the Mediterranean diet? J Transl Med. 2015;13:18. https://doi.org/10.1186/s12967-014-0372-1.

20. Barrea L, Fabbrocini G, Annunziata G, Muscogiuri G, Donnarumma M, Marasca C, et al. Role of nutrition and adherence to the mediterranean diet in the multidisciplinary approach of hidradenitis suppurativa: evaluation of nutritional status and its association with severity of disease. Nutrients. 2018;1 1(1):57-74. https://doi.org/10.3390/nu11010057.

21. Barrea L, Arnone A, Annunziata G, Muscogiuri G, Laudisio D, Salzano C, et al. Adherence to the mediterranean diet, dietary patterns and body composition in women with polycystic ovary syndrome (PCOS). Nutrients. 2019;11(10):2278-99. https://doi.org/10.3390/nu11102278.

22. Barrea L, Marzullo P, Muscogiuri G, Di Somma C, Scacchi M, Orio F, et al. Source and amount of carbohydrate in the diet and inflammation in women with polycystic ovary syndrome. Nutr Res Rev. 2018;31(2):291301. https://doi.org/10.1017/S0954422418000136.

23. Laudisio D, Castellucci B, Barrea L, Pugliese G, Savastano S, Colao A, et al. Mediterranean diet and breast cancer risk: a narrative review. Minerva Endocrinol. 2020. https://doi.org/10.23736/S0391-1977.20.03266-6 (Online ahead of print).

24. Laudisio D, Barrea L, Muscogiuri G, Annunziata G, Colao A, Savastano S. Breast cancer prevention in premenopausal women: Role of the Mediterranean diet and its components. Nutr Res Rev. 2020;33(1):19-32. https:// doi.org/10.1017/S0954422419000167.

25. Laudisio D, Muscogiuri G, Barrea L, Savastano S, Colao A. Obesity and breast cancer in premenopausal women: current evidence and future perspectives. Eur J Obstet Gynecol Reprod Biol. 2018;230:217-21. https:// doi.org/10.1016/j.ejogrb.2018.03.050.

26. Pugliese G, Barrea L, Laudisio D, Aprano S, Castellucci B, Framondi L, et al. Mediterranean diet as tool to manage obesity in menopause: a narrative review. Nutrition. 2020;79-80:110991-7. https://doi.org/10.1016/j.nut. 2020.110991

27. Barrea L, Pugliese G, Laudisio D, Colao A, Savastano S, Muscogiuri G. Mediterranean diet as medical prescription in menopausal women with obesity: a practical guide for nutritionists. Crit Rev Food Sci Nutr. 2021;61(7):1201-11. https://doi.org/10.1080/10408398.2020.1755220.

28. Barrea L, Di Somma C, Muscogiuri G, Tarantino G, Tenore GC, Orio F, et al. Nutrition, inflammation and liver-spleen axis. Crit Rev Food Sci Nutr. 2018;58(18):3141-58. https://doi.org/10.1080/10408398.2017.1353479.
29. Barrea L, Muscogiuri G, Frias-Toral E, Laudisio D, Pugliese G, Castellucci $B$, et al. Nutrition and immune system: from the Mediterranean diet to dietary supplementary through the microbiota. Crit Rev Food Sci Nutr. 2020;1-25. https://doi.org/10.1080/10408398.2020.1792826.

30. Tosti V, Bertozzi B, Fontana L. Health benefits of the mediterranean diet: metabolic and molecular mechanisms. J Gerontol A Biol Sci Med Sci. 2018;73(3):318-26. https://doi.org/10.1093/gerona/gl×227.

31. Skroza N, Tolino E, Proietti I, Bernardini N, Nicolucci F, Viola G, et al. Mediterranean diet and familial dysmetabolism as factors influencing the development of acne. Scand J Public Health. 2012;40(5):466-74. https:// doi.org/10.1177/1403494812454235.

32. Chiplonkar S, Kajale N, Ekbote V, Mandlik R, Parthasarathy L, Khadilkar V, et al. Validation of bioelectric impedance analysis against dual-energy $X$-ray absorptiometry for assessment of body composition in Indian children aged 5 to 18 years. Indian Pediatr. 2017;54(11):919-24. https:// doi.org/10.1007/s13312-017-1182-3.

33. Huang AC, Chen YY, Chuang CL, Chiang LM, Lu HK, Lin HC, et al. Crossmode bioelectrical impedance analysis in a standing position for estimating fat-free mass validated against dual-energy $x$-ray absorptiometry. Nutr Res. 2015;35(11):982-9. https://doi.org/10.1016/j.nutres.2015.08.005.

34. Tomeleri CM, Cavaglieri CR, de Souza MF, Cavalcante EF, Antunes M, Nabbuco HCG, et al. Phase angle is related with inflammatory and oxidative stress biomarkers in older women. Exp Gerontol. 2018;102:12-8. https:// doi.org/10.1016/j.exger.2017.11.019.

35. Lukaski HC, Kyle UG, Kondrup J. Assessment of adult malnutrition and prognosis with bioelectrical impedance analysis: phase angle and impedance ratio. Curr Opin Clin Nutr Metab Care. 2017;20(5):330-9. https://doi. org/10.1097/MCO.0000000000000387.

36. Barbosa-Silva MCG, Barros AJD. Bioelectrical impedance analysis in clinical practice: a new perspective on its use beyond body composition equations. Curr Opin Clin Nutr Metab Care. 2005;8(3):311-7. https://doi. org/10.1097/01.mco.0000165011.69943.39.

37. Norman K, Stobäus N, Pirlich M, Bosy-Westphal A. Bioelectrical phase angle and impedance vector analysis_-clinical relevance and applicability of impedance parameters. Clin Nutr. 2012;31(6):854-61. https://doi. org/10.1016/j.clnu.2012.05.008.

38. Stobäus N, Pirlich M, Valentini L, Schulzke JD, Norman K. Determinants of bioelectrical phase angle in disease. Br J Nutr. 2004;92(6):957-62. https:// doi.org/10.1079/bjn20041292.

39. Gonzalez MC, Barbosa-Silva TG, Bielemann RM, Gallagher D, Heymsfield SB. Phase angle and its determinants in healthy subjects: influence of body composition. Am J Clin Nutr. 2016;103(3):712-6. https://doi.org/10. 3945/ajcn.115.116772.

40. Kyle UG, Bosaeus I, De Lorenzo AD, Deurenberg P, Elia M, Gómez JM, et al. Bioelectrical impedance analysis_-Part II: utilization in clinical practice. Clin Nutr. 2004;23(6):1430-53. https://doi.org/10.1016/j.cInu.2004.09.012.

41. Norman K, Stobäus N, Zocher D, Bosy-Westphal A, Szramek A, Scheufele $\mathrm{R}$, et al. Cutoff percentiles of bioelectrical phase angle predict functionality, quality of life, and mortality in patients with cancer. Am J Clin Nutr. 2010;92(3):612-9. https://doi.org/10.3945/ajen.2010.29215.

42. Muscogiuri G, Barrea L, Laudisio D, Pugliese G, Aprano S, Framondi L, et al. The opera prevention project. Int J Food Sci Nutr. 2021;72(1):1-3. https:// doi.org/10.1080/09637486.2020.1765152.

43. Legro RS, Arslanian SA, Ehrmann DA, Hoeger KM, Murad MH, Pasquali $R$, et al. Diagnosis and treatment of polycystic ovary syndrome: an endocrine society clinical practice guideline. J Clin Endocrinol Metab. 2013;98(12):4565-92. https://doi.org/10.1210/jc.2013-2350.

44. Muscogiuri G, Barrea L, Di Somma C, Laudisio D, Salzano C, Pugliese G, et al. Sex differences of vitamin D status across BMI classes: an observational prospective cohort study. Nutrients. 2019;11(12):3034-46. https:// doi.org/10.3390/nu11123034.

45. Barrea L, Muscogiuri G, Laudisio D, Pugliese G, de Alteriis G, Colao A, et al. Influence of the mediterranean diet on 25-hydroxyvitamin $D$ levels in adults. Nutrients. 2020;12(5):1439-60. https://doi.org/10.3390/nu120 51439.

46. Barrea L, Muscogiuri G, Di Somma C, Annunziata G, Megna M, Falco A, et al. Coffee consumption, metabolic syndrome and clinical severity of psoriasis: good or bad stuff? Arch Toxicol. 2018;92(5):1831-45. https://doi. org/10.1007/s00204-018-2193-0.

47. Barrea L, Tarantino G, Di SC, Muscogiuri G, Macchia PE, Falco A, et al. Adherence to the mediterranean diet and circulating levels of sirtuin 
4 in obese patients: a novel association. Oxid Med Cell Longev. 2017;2017:6101254-69. https://doi.org/10.1155/2017/6101254.

48. Barrea L, Di Somma C, Macchia PE, Falco A, Savanelli MC, Orio F, et al. Influence of nutrition on somatotropic axis: milk consumption in adult individuals with moderate-severe obesity. Clin Nutr. 2017;36(1):293301. https://doi.org/10.1016/j.cInu.2015.12.007.

49. Savanelli MC, Scarano E, Muscogiuri G, Barrea L, Vuolo L, Rubino $M$, et al. Cardiovascular risk in adult hypopituitaric patients with growth hormone deficiency: is there a role for vitamin D? Endocrine. 2016;52(1):111-9. https://doi.org/10.1007/s12020-015-0779-3.

50. Savastano S, Di Somma C, Colao A, Barrea L, Orio F, Finelli C, et al. Preliminary data on the relationship between circulating levels of Sirtuin 4, anthropometric and metabolic parameters in obese subjects according to growth hormone/insulin-like growth factor-1 status. Growth Horm IGF Res. 2015;25(1):28-33. https://doi.org/10.1016/j.ghir.2014.10. 006.

51. Barrea L, Muscogiuri G, Annunziata G, Laudisio D, Tenore GC, Colao A, et al. A new light on vitamin d in obesity: a novel association with trimethylamine-n-oxide (tmao). Nutrients. 2019;11(6):1310-25. https:// doi.org/10.3390/nu11061310

52. Barrea L, Pugliese G, Framondi L, Di Matteo R, Laudisio D, Savastano S, et al. Does Sars-Cov-2 threaten our dreams? Effect of quarantine on sleep quality and body mass index. J Transl Med. 2020;18(1):318-29. https://doi.org/10.1186/s12967-020-02465-y.

53. World Health Organization. WHO [Internet]. [cited 2021 February 4]. Available from: http://www.euro.who.int/en/health-topics/disea se-prevention/nutrition/a-healthy-lifestyle/body-mass-index-bmi. Accessed 21 Feb 2021.

54. National Center for Health Statistics. Accessed 21 Feb 2021.

55. Nishida C, Ko GT, Kumanyika S. Body fat distribution and noncommunicable diseases in populations: overview of the 2008 WHO Expert Consultation on Waist Circumference and Waist-Hip Ratio. Eur J Clin Nutr. 2010;64(1):2-5. https://doi.org/10.1038/ejen.2009.139.

56. Barrea L, Muscogiuri G, Macchia PE, Di Somma C, Falco A, Savanelli MC, et al. Mediterranean diet and phase angle in a sample of adult population: results of a pilot study. Nutrients. 2017;9(2):151-65. https://doi. org/10.3390/nu9020151.

57. Barrea L, Muscogiuri G, Pugliese G, Aprano S, de Alteriis G, Di Somma $C$, et al. The sun's vitamin in adult patients affected by Prader-Willi syndrome. Nutrients. 2020;12(4):1132-48. https://doi.org/10.3390/nu120 41132.

58. Barrea L, Pugliese G, de Alteriis G, Colao A, Savastano S, Muscogiuri G. Phase angle: could be an easy tool to detect low-grade systemic inflammation in adults affected by Prader-Willi syndrome? Nutrients. 2020;12(7):2065-79. https://doi.org/10.3390/nu12072065.

59. Kushner RF. Bioelectrical impedance analysis: a review of principles and applications. J Am Coll Nutr. 1992;11 (2):199-209.

60. Xu Y, Xie X, Duan Y, Wang L, Cheng Z, Cheng J. A review of impedance measurements of whole cells. Biosens Bioelectron. 2016;77:824-36. https://doi.org/10.1016/j.bios.2015.10.027.

61. Barbosa-Silva MCG, Barros AJD, Wang J, Heymsfield SB, Pierson RN. Bioelectrical impedance analysis: population reference values for phase angle by age and sex. Am J Clin Nutr. 2005;82(1):49-52. https://doi.org/ 10.1093/ajcn.82.1.49.

62. Martínez-González MA, García-Arellano A, Toledo E, Salas-Salvadó J, Buil-Cosiales P, Corella D, et al. A 14-item mediterranean diet assessment tool and obesity indexes among high-risk subjects: the PREDIMED trial. PLoS ONE. 2012;7(8):e43134. https://doi.org/10.1371/journal. pone.0043134.

63. Barrea L, Muscogiuri G, Di Somma C, Tramontano G, De Luca V, Illario M, et al. Association between Mediterranean diet and hand grip strength in older adult women. Clin Nutr. 2019;38(2):721-9. https://doi.org/10.1016/j. Clnu.2018.03.012.

64. Barrea L, Altieri B, Muscogiuri G, Laudisio D, Annunziata G, Colao A, et al. Impact of nutritional status on gastroenteropancreatic neuroendocrine tumors (GEP-NET) aggressiveness. Nutrients. 2018;10(12):1854-72. https://doi.org/10.3390/nu10121854.

65. Muscogiuri G, Barrea L, Di Somma C, Altieri B, Vecchiarini M, Orio F, et al. Patient empowerment and the Mediterranean diet as a possible tool to tackle prediabetes associated with overweight or obesity: a pilot study. Hormones (Athens). 2019;18(1):75-84. https://doi.org/10.1007/ s42000-018-0090-9.

66. Doshi A, Zaheer A, Stiller MJ. A comparison of current acne grading systems and proposal of a novel system. Int J Dermatol. 1997;36(6):416-8. https://doi.org/10.1046/j.1365-4362.1997.00099.x.

67. Dall'Oglio F, Fabbrocini G, Tedeschi A, Donnarumma M, Chiodini P, Micali G. Licochalcone a in combination with salicylic acid as fluid based and hydroxy-complex $10 \%$ cream for the treatment of mild acne: a multicenter prospective trial. Clin Cosmet Investig Dermatol. 2019;12:961-7. https://doi.org/10.2147/CCID.S206935.

68. Selberg O, Selberg D. Norms and correlates of bioimpedance phase angle in healthy human subjects, hospitalized patients, and patients with liver cirrhosis. Eur J Appl Physiol. 2002;86(6):509-16. https://doi.org/10.1007/ s00421-001-0570-4.

69. Lowe GDO, Fowkes FGR, Dawes J, Donnan PT, Lennie SE, Housley E. Blood viscosity, fibrinogen, and activation of coagulation and leukocytes in peripheral arterial disease and the normal population in the Edinburgh artery study. Circulation. 1993;87(6):1915-20. https://doi.org/10.1161/01. cir.87.6.1915.

70. Barrea L, Macchia PE, Di Somma C, Napolitano M, Balato A, Falco A, et al. Bioelectrical phase angle and psoriasis: a novel association with psoriasis severity, quality of life and metabolic syndrome. J Transl Med. 2016;14(1):130-42. https://doi.org/10.1186/s12967-016-0889-6.

71. Barrea L, Muscogiuri G, Laudisio D, Di Somma C, Salzano C, Pugliese G, et al. Phase angle: a possible biomarker to quantify inflammation in subjects with obesity and 25(OH)D deficiency. Nutrients. 2019;1 1(8):1747-63. https://doi.org/10.3390/nu11081747.

72. Musso CG, Jauregui JR, Macías Núñez JF. Frailty phenotype and chronic kidney disease: a review of the literature. Int Urol Nephrol. 2015;47(11):1801-7. https://doi.org/10.1007/s11255-015-1112-z.

73. Del Prete M, Mauriello MC, Faggiano A, Di Somma C, Monfrecola $\mathrm{G}$, Fabbrocini $\mathrm{G}$, et al. Insulin resistance and acne: a new risk factor for men? Endocrine. 2012;42(3):555-60. https://doi.org/10.1007/ s12020-012-9647-6.

74. Bowe WP, Joshi SS, Shalita AR. Diet and acne. J Am Acad Dermatol. 2010;63(1):124-41. https://doi.org/10.1016/j.jaad.2009.07.043.

75. Atkinson FS, Foster-Powell K, Brand-Miller JC. International tables of glycemic index and glycemic load values: 2008. Diabetes Care. 2008;31(12):2281-3. https://doi.org/10.2337/dc08-1239.

76. Balić A, Vlašić D, Žužul K, Marinović B, Mokos ZB. Omega-3 versus Omega-6 polyunsaturated fatty acids in the prevention and treatment of inflammatory skin diseases. Int J Mol Sci. 2020;21(3):741-67. https://doi. org/10.3390/ijms21030741.

77. Simopoulos AP. An increase in the Omega-6/Omega-3 fatty acid ratio increases the risk for obesity. Nutrients. 2016;8(3):128-45. https://doi.org/ 10.3390/nu8030128.

78. Harris WS. The Omega-6:Omega-3 ratio: a critical appraisal and possible successor. Prostaglandins Leukot Essent Fatty Acids. 2018;132:34-40. https://doi.org/10.1016/j.plefa.2018.03.003.

79. Heng AHS, Chew FT. Systematic review of the epidemiology of acne vulgaris. Sci Rep. 2020;10(1):5754-83. https://doi.org/10.1038/ s41598-020-62715-3.

80. Burris J, Rietkerk W, Woolf K. Relationships of self-reported dietary factors and perceived acne severity in a cohort of New York young adults. J Acad Nutr Diet. 2014;114(3):384-92. https://doi.org/10.1016/j.jand.2013.11.010.

81. Dai R, Hua W, Chen W, Xiong L, Li L. The effect of milk consumption on acne: a meta-analysis of observational studies. J Eur Acad Dermatol Venereol. 2018;32(12):2244-53. https://doi.org/10.1111/jdv.15204.

82. Hu FB. Dietary pattern analysis: a new direction in nutritional epidemiology. Curr Opin Lipidol. 2002;13(1):3-9. https://doi.org/10.1097/00041433200202000-00002.

83. Shahidi F, Ambigaipalan P. Omega-3 polyunsaturated fatty acids and their health benefits. Annu Rev Food Sci Technol. 2018;9:345-81. https://doi. org/10.1146/annurev-food-111317-095850.

84. Desai MS, Seekatz AM, Koropatkin NM, Kamada N, Hickey CA, Wolter $\mathrm{M}$, et al. A dietary fiber-deprived gut microbiota degrades the colonic mucus barrier and enhances pathogen susceptibility. Cell. 2016;167(5):1339-1353.e21. https://doi.org/10.1016/j.cell.2016.10.043.

85. Bowe WP, Patel N, Logan AC. Acne vulgaris: the role of oxidative stress and the potential therapeutic value of local and systemic antioxidants. J Drugs Dermatol. 2012;11(6):742-6. 
86. Abiemo EE, Alonso A, Nettleton JA, Steffen LM, Bertoni AG, Jain A, et al. Relationships of the Mediterranean dietary pattern with insulin resistance and diabetes incidence in the Multi-Ethnic Study of Atherosclerosis (MESA). Br J Nutr. 2013;109(8):1490-7. https://doi.org/10.1017/S0007 114512003339

87. Bendall CL, Mayr HL, Opie RS, Bes-Rastrollo M, Itsiopoulos C, Thomas CJ. Central obesity and the Mediterranean diet: a systematic review of intervention trials. Crit Rev Food Sci Nutr. 2018;58(18):3070-84. https:// doi.org/10.1080/10408398.2017.1351917.

88. Barrea L, Annunziata G, Muscogiuri G, Laudisio D, Di Somma C, Maisto $\mathrm{M}$, et al. Trimethylamine $\mathrm{N}$-oxide, Mediterranean diet, and nutrition in healthy, normal-weight adults: also a matter of sex? Nutrition. 2019;62:717. https://doi.org/10.1016/j.nut.2018.11.015.
89. Muscogiuri G, Barrea L, Laudisio D, Di Somma C, Pugliese G, Salzano C, et al. Somatotropic axis and obesity: is there any role for the Mediterranean diet? Nutrients. 2019;11(9):2228-43. https://doi.org/10.3390/nu110 92228.

90. Schröder H, Fitó M, Estruch R, Martínez-González MA, Corella D, Salas-Salvadó J, et al. A short screener is valid for assessing Mediterranean diet adherence among older spanish men and women. J Nutr. 2011;141(6):1140-5. https://doi.org/10.3945/jn.110.135566.

\section{Publisher's Note}

Springer Nature remains neutral with regard to jurisdictional claims in published maps and institutional affiliations.
Ready to submit your research? Choose BMC and benefit from:

- fast, convenient online submission

- thorough peer review by experienced researchers in your field

- rapid publication on acceptance

- support for research data, including large and complex data types

- gold Open Access which fosters wider collaboration and increased citations

- maximum visibility for your research: over 100M website views per year

At BMC, research is always in progress.

Learn more biomedcentral.com/submissions 